\title{
Effectiveness of Subliminal Messages and Their Influence on People's Choices
}

\author{
Rania Karam, PhD \\ American University of Culture \& Education, Beirut, Lebanon \\ Mohamad Abou Haidar, PhD \\ Lebanese University, Beirut, Lebanon
}

Abbas Khawaja, PhD

Al Jinan University, Beirut, Lebanon

Ghida Al Laziki, MBA

Arts, Sciences and Technology University in Lebanon. Kaslik, Lebanon

doi: 10.19044/esj.2017.v13n17p262 URL:http://dx.doi.org/10.19044/esj.2017.v13n17p262

\begin{abstract}
This article provides definitions for the conscious and subconscious minds, and shows their relation with the subliminal messages which are also defined. The subliminal CD's, the way they function, and how they are recorded are explained in details. In addition, an interview with an expert in subliminal messages was conducted to enrich the article with more technical details. Moreover, the main objective of the research study was to show the effectiveness of the subliminal messages, and therefore to prove the influence they have on people's choices in the auditory system. For this purpose, two experiments were carried out. The results proved that the experimental hypothesis is true: subliminal messages affect and influence the participants' choice.
\end{abstract}

Keywords : Subliminal, messages, influence, participants, choice

\section{Introduction}

Students, employees, managers, scientists, athletes, parents, or husbands and wives, have, in a way, wishes and goals (short term or long term) that they want and work hard to achieve. However, many people, also, fail to achieve their predetermined or already set goals because of many reasons. One of these reasons, which is considered important and critical, is that a lot of people can not easily control themselves: their mind, thoughts, feelings, attitudes, or behavior. In fact, the conscious mind, which is the part of the mind that is responsible of all the decision-making and all the necessary reasoning, with time, has developed a certain kind of resistance to 
changes. That is why people can not easily change. However, there is another part in the mind, the subconscious mind, which can, in a certain way, be programmed and can receive suggestions or orders to make changes, without arguing or reasoning. In fact, those people who were able to program and give suggestions and orders to their subconscious mind, experienced great changes in their attitudes, habits, feelings, and behavior.

How can a person program and give suggestions and orders to the subconscious mind? Well, different people might use different methods. They might use self-hypnosis techniques; but it is not simple and requires a lot of training. They might use meditation techniques; but also, it needs time and a lot of concentration. However, other than these two mentioned methods, there is one important, simple, easy and effective method, but not commonly known, used in programming the subconscious mind: it is passing to the mind suggestions through subliminal messages.

What are exactly subliminal messages? For what and how are they used? And to what extent they are effective? Well, this article provides answers to these questions and many others. In fact, this article shows and proves the effectiveness of subliminal messages and their influence on people's choices. The main objectives are to explain how subliminal programming works on the subconscious mind, and how therefore, subliminal messages can have a considerable influence over people's choices, thoughts, attitudes, preferences, or behavior. In addition, this article shows how subliminal recordings (auditory system) can be considered an effective tool for personal development. Therefore, in order to achieve the objectives of this article, many steps are to take place. As a first step; and since subliminal messages or subliminal programming deals with the subconscious mind, the difference between the two parts of the mind; conscious and subconscious, and how they work and function are explained in the literature review. As a second step, the link between subliminal messages and the subconscious mind is clarified, and definitions for subliminal programming or messages are provided. This article explains how these subliminal messages function and the effect they have on the auditory and visual systems, their evolution, and their different usage. In addition to the previously mentioned points, an interview with an expert in subliminal programming enriches the article with more technical details especially on how to record a subliminal CD.

Moreover, in order to prove the effectiveness and the influence that subliminal messages have on people's choices, preferences, attitudes, and behavior, two experiments took take place with some volunteers. The volunteers listened to subliminal CD's recorded in advance where subliminal messages were integrated in some music. Afterwards, all the participants were asked to choose one item (a color in the first experiment and a three- 
digit number in the second) among different items. Then, they had to answer a list of questions about the reason behind choosing the color or the number, and whether they liked the music, and if they heard any words with the music. The results of the two experiments were evaluated, compared, analyzed, and a conclusion was drawn concerning the influence and the effectiveness of subliminal messages on people's choices, as an example.

\section{Literature review}

Since subliminal programming is concerned with the mind and deals directly with its subconscious part, a definition of the mind and its parts is very essential to start with. According to The American Heritage Dictionary of the English Language, the mind is defined as "the collective conscious and unconscious processes in a sentient organism that direct and influence mental and physical behavior". Therefore, it is only one mind, but this mind possesses two distinct and characteristic functional parts. Many different names have been given to the two parts of the mind: objective - subjective mind, walking - sleeping mind, voluntary - involuntary mind, and finally and the most known names are conscious and subconscious mind.

The conscious and subconscious are not two minds, but they are two distinct parts of one mind. A person chooses a book, a home, or a partner with the conscious mind which is the reasoning mind. A person, in fact, makes all the decisions with his conscious mind. On the other hand, all the vital functions of a person, like digestion, blood circulation, and breathing, and without any conscious choice on the person's part are carried on by the subconscious mind through processes independent of the conscious control.

According to Dr. Joseph Murphy, "the most important point to remember is this: once the subconscious mind accepts an idea, it begins to execute it." In fact, the subconscious mind accepts what is impressed upon it, or what the person consciously believes. The subconscious mind does not reason things out as the conscious mind does. Dr. Joseph Murphy compares the subconscious mind to a bed of soil that accepts any kind of seeds, good or bad, with the thoughts that are active, being the seeds. In addition, Daniel Olson, hypnotist, author, trainer, and consultant, compares the subconscious mind to the memory bank of a modern computer. The computer does not question the information placed in its memory. It just uses the information. The same for the subconscious mind, the mind does not question what it is stored in it; it only uses the information to solve problems.

It is now clear how and to what extent the subconscious mind works. The ability to bypass our conscious awareness by masking the messages from the conscious mind and direct them at the subconscious mind is the key to influencing our thoughts, feelings, behaviors. In fact this process is called: subliminal programming or subliminal messages. 
It is the subconscious mind that the subliminal programming is concerned with. According to Skeptic's Dictionary, the subliminal is below the liminal (the smallest detectible sensation). Anything truly below the level of detectable sensation could not, by definition, be perceived. However, the subliminal is generally said to be below the threshold of conscious perception. Moreover, the website www.subliminal-cd.com writes that "by repeatedly and subtly programming our subconscious mind with thought patterns, affirmations, directions and suggestions, we can effortlessly change bad habits, levels of confidence, self-esteem, and a variety of emotional and behavior maladies or short comings."

Furthermore, subliminal messages can be presented to the subconscious mind either through the visual system (viewers) or the auditory system (listeners). In fact, subliminal messages started mainly as an advertising application using the visual system, and then, they were used as self-help tapes using the auditory system:

- Advertising application (visual system): The belief in the power of subliminal messages to affect or manipulate the behavior of the viewer originated in September 1957 with James Vicary, an advertising promoter. Vicary claimed to increase popcorn sales by $58 \%$ and Coke sales by $18 \%$ in a New Jersey movie theatre. Vicary used the subliminal messages technique: It was done by flashing very briefly the messages "Drink Coca Cola" and "Hungry - Eat Popcorn" for a period of six weeks to 45,699 viewer watching the film Picnic. The messages were flashed for 3/1000 of a second every five minutes. The duration of the message was so short that they were never perceived. Moreover, many people believe that most advertisements contain hidden sexual images or words that affect our susceptibility to the ads (refer to figure 1). In fact, the belief and the technique of subliminal messaging reached its apex in 1980 with the publication of The Clam - Plate Orgy and Other Subliminals the Media Use to Manipulate Your Behavior, by Wilson Bryan Key. The idea of Key is that advertisers are using subliminal messages of a sexual nature in order to affect behavior. Key claims that the subconscious mind processes subliminal messages at the speed of light. Moreover, and according to Key, although embedded words are not consciously perceived, they are unconsciously perceived, and they can elicit sexual arousal which in turn makes the consumer more attracted to the products. 


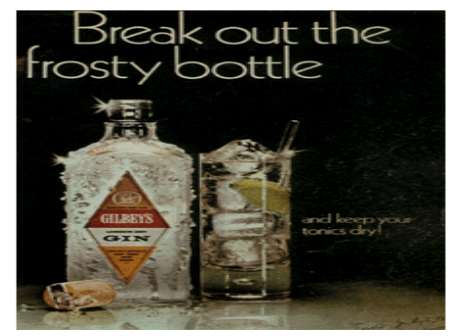

Figure 1: Ad for Gilbey’s Gin (the word sex is embedded in the ice cubes)

- Self-help tapes or CD's (auditory system): After the claims of September 1957, concerning the subliminal messages in the advertising (coca cola and popcorn), television commercials, magazine ad, and bookstores, started promoting subliminal tapes and CD's that promise to make dramatic changes in people's mental and psychological health: like weight loss, improvement of sexual function, and relief from constipation.

Other than these two usages for subliminal messages, there is another one, but unfortunately considered a bad usage: subliminal messages in Rock and Roll songs (Subliminal suicide). As an example, in 1985, in Nevada, two boys committed suicide. Their families sued CBS Records Inc., and Judas Priest, the bad boys of British heavy metal, for supposedly placing in a song a subliminal message "Do It", that invited and contributed in the suicides of the two teenagers. The subliminal message was integrated in the song "Better By You, Better Than Me”, from the band's 1978. As a matter of fact, many cases of subliminal suicides took place also in Lebanon. One of these cases, from Al Balad Journal, talks about a young man who threw himself from a very high place in Batroun in front of his friends. His friends, who were watching him, believed that his suicide was nothing but a gift for Satan. They believe that they are receiving messages from the rock music that they listen to frequently, inviting them to kill themselves for Satan.

Subliminal messages in rock songs provide an example of how these subliminals can be used for bad purposes. However, these subliminals can also be used for good purposes: they can be used as a self-help and personal development tool. In fact, and as mentioned before, the main point in subliminal programming is to bypass the conscious mind since the conscious mind has created over the years a certain "conscious resistance" to change. Therefore, the conscious mind has its own version of reality which can not be simply changed by only wanting that. However, people can improve any aspect of their life using subliminal messages. In fact, people can use subliminal messages when they decide to make changes in their life. These subliminal messages can be used for many purposes: to stop smoking, lose weight, overcome fears, remove stress or bad habits. Some modules might 
be about better teaching, better education, public speaking, improvement of salesmanship, sexual seduction, peaceful pregnancy... They are used also in some large retail stores to encourage "listeners" not to steal. For more details, consumers spend more than \$50 million each year on subliminal selfhelp products (Journal of Advertising Research, reported by Dennis Love, Sacramento Bee, 9-14-2000)

These subliminal messages, regardless of the content or module, can pass to the subconscious mind, either through the visual system (viewers) or the auditory system (listeners). In the visual system, one of the ways that this can be done is with using special software like "Subliminal Power". Once it is downloaded on the computer, it will run in the background. It will flash subtle random-area, low-contrast, and 100-millisecond messages every five seconds, while people are working. The viewers will not notice or perceive the message. People will only have to choose the topic or the program they want, and then run the software. However, in the auditory system, the process is different. People can listen to subliminal tapes and CD's, when they are at work, at home, watching TV, doing the housework, or even thinking of something else. The mind will absorb the subliminal message wherever people are. Those people wishing to get benefit from the subliminal recordings can listen to them at any time of the day. People can even listen to them while sleeping. In fact, people don't have to find special time to use these recordings. They can be played continuously, all day long. The longer people listen to them, the more dramatic the results are. The only minor effort that people have to do is to listen to the recordings. No other effort has to be done.

In this article, the emphasis is on passing subliminal messages through the auditory system and not the visual system. Therefore, in the research studies, the way subliminal messages function in the auditory system is explained in details. In addition, experiments to measure the effectiveness of subliminal messages took place. In the experiments, the participants had to listen to subliminal CD's recorded in advance; the way the CD's were recorded is explained also in the following section of this article.

\section{Research Studies}

Before proceeding to the experiment and the way the subliminal CD's were recorded, it is very essential to explain the types of subliminal messages. Many research show that there are four types of subliminal messages. These four types are listed below:

Those which are presented at energy levels that are too weak to be detected by the audience; eg: flashing the words "eat popcorn" onto a screen 
so quickly that the audience is not aware of them. (called: sub threshold stimuli)

Those which are hidden from the audience by the presentation of some others, overriding stimuli; eg: briefly presenting the stimulus immediately followed by a bright flash of light. (called: masked stimuli)

Those which are presented in such a way that the embedded figure is unlikely to be separated from its figural context; eg: hiding the figure of a naked body in the curves and lines of a picture of an ice cube. (called: unattended stimuli)

Those which are words and pictures blurred or distorted to the point that they are unrecognizable; eg: commands recorded backwards and inserted into popular music. (called: figurally transformed stimuli)

Due to the wide difference that exists among the four mentioned types of subliminal messages, the research studies and the experiments were limited only to the sub threshold recordings or messages. These recordings do two things: as first step, special sounds or music place the listener in a light trance or simply draw his attention in a certain way to make him more receptive to the subliminal message. Then, the second step will be the subliminal message in itself. It will begin to write deeply into the brain or the subconscious mind without the awareness or without being filtered by the conscious mind.

Regarding the way subliminal CD's function and how they affect the listener, an interview was conducted with Mr. Zygmunt Niewiadomski, an expert in subliminal programming. Mr. Niewiadomski explained and summarized the process as follows: Once the subliminal message is caught by the brain, people will find themselves deeply changed, and their conscious mind will start finding excuses in order to justify the new behavior. For example, if a person is trying to overcome his fear of darkness, the conscious mind will try to stop him, making him remember all the time, how scary is the darkness. The conscious mind fears the change; with time, it has developed a certain kind of resistance to change. $\mathrm{Mr}$. Niewiadomski added that the conscious mind keeps giving orders to the subconscious not to change. But when people listen to a subliminal CD or tape and since the music chosen helps the listener to go into a light trance, the conscious mind will be like asleep and only the subconscious mind will be awake; consequently, it will receive orders, inputs and suggestions without being stopped by the conscious mind. At this stage, the subconscious will give orders to the conscious, and the conscious will start to think that darkness is not scary; there is no reason to be scared of darkness; darkness is relaxing... Then the conscious mind will try to protect this new state of the mind: "I am not afraid of darkness; I enjoy darkness..." 
Moreover, and in order to investigate the questions and the issues raised in the previous sections, and in order to measure the effectiveness of the subliminal messages in the audio system, experiments were conducted to prove and measure the influence subliminal messages can have on people's choice for colors and numbers. This was done in many stages: first, recording the subliminal $C D$; second, doing the test; third, answering a list of questions; and finally, analyzing the results.

Recording the subliminal CD is the first step to start with. As a matter of fact, a subliminal message (audio system) must do many essential things: It must clearly define and communicate the goal to the subconscious; it must communicate the goal as if it has already happened, or is happening now; it must phrase each suggestion three different ways for maximum impact; and it must attach positive emotions to the completion of the goal. Therefore, according to Mr. Niewiadomski, recording the subliminal CD for the experiment is done in many steps:

Construct the verbal commands: Positive and first person affirmations should always be used. Using 'not' in subliminal messages can have serious side effects. The statement should be direct ("I am confident") and should give the listener permission ("It is OK for me to choose red"). The scripts don't have to be long, but should be repeated over and over which is initial to influence the subconscious mind.

Record the verbal commands at a subliminal level that only the subconscious mind can perceive. The conscious mind hears only the music or the sound mask.

Layout the sound mask (raindrops falling...): This can be done using music extraction software (Ripper) to extract the contents of any CD or already found sound masks or sound effects. The music or sound mask puts the listener into a relaxed Alpha brain state and makes him or her more receptive to the message (verbal commands). For more details, the brain is producing electrical impulses all the time. These currents of electricity, or brainwaves, are measured in amplitude and frequency. The frequency determines the category of brainwave - beta, alpha, theta, and delta (refer to figure 2). The combination of these categories determines or underlies the state of consciousness at any given time. 


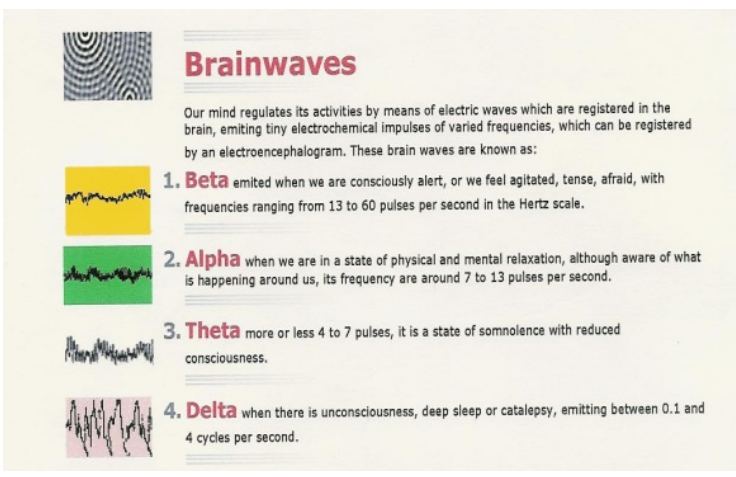

Figure 2: The four categories of brainwaves

Layout the subliminal under the sound mask: This is done using an audio mixing software (Mixer) or Adobe Audition (refer to figure 3).

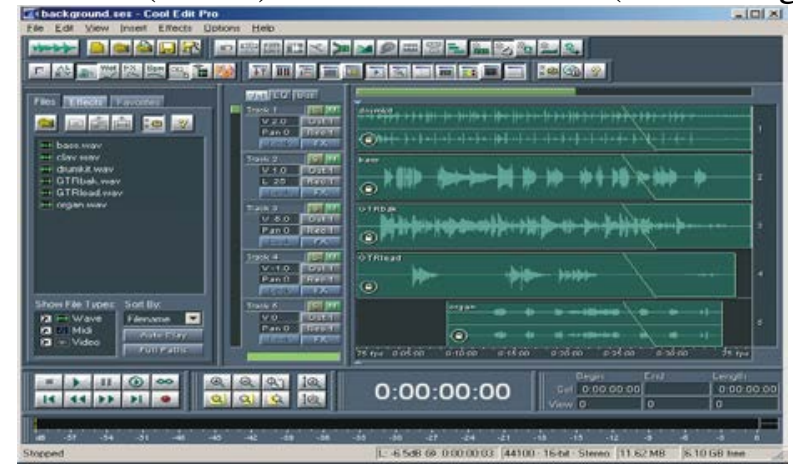

Figure 3: Adobe Audition

Export to MP3, WAV, or other file formats: Once the file is exported to MP3, it can be listened to on any CD player at any time.

The experiments: Once the subliminal CD's were recorded following the previous steps, they were ready to be used in the experiment. For any experimental research, many points should be clarified.

Goal/objective: The purpose of the experiment is to measure the effectiveness of subliminal messages and the influence they have on participants' choice of colors and of numbers. (The results are concrete and measurable.)

Experimental Hypothesis: Subliminal messages influence and affect the participants' choice.

Participants: Twenty participants are chosen randomly (students, employees, males or females), but they all have to speak and understand English because the subliminal messages are in English.

Material of the experiment: The materials needed for the experiment are a CD player, the subliminal CD's recorded in advance, one paper with three different colors on it, and another one where five different three-digit 
numbers are written randomly (refer to figure 4), and photocopied papers with a list of questions (refer to figure 5) to be filled by the participants when they finish listening to the subliminal CD.

Procedure: The participants, each one alone, listen to a subliminal $\mathrm{CD}$ with a subliminal message telling them to choose the red color (the colors are blue, red, and green) in the first experiment, and to choose the three-digit number 128 (the numbers are 373, 745, 237, 128, and 452) in the second experiment. They have to listen to the CD for around four to five minutes. The participants, in both experiments, are not told in advance that they have to choose a color or a number, because of the concept of change resistance already explained before in the article. They are only told that they have to answer some questions concerning what they listened to. They are asked to relax and listen to the CD. The experiment is taking place in a controlled environment where the full attention of the participants is devoted to the subliminal message. When they finish listening to the $\mathrm{CD}$, they have to choose, as mentioned before, a color in the first experiment and a number in the second experiment, and then they fill the questionnaire.

\section{Please, read the following numbers and then choose one:}

Figure 4: The participants of experiment no.2 have to choose one number from the above list

Experimental Research: Subliminal Messages

\begin{tabular}{|c|c|c|c|}
\hline \multicolumn{4}{|l|}{ Date: } \\
\hline \multicolumn{4}{|l|}{ Name: } \\
\hline What number did you choose? & & $\begin{array}{llll}373 & 745 & 237 & 128\end{array}$ & 452 \\
\hline \multicolumn{4}{|l|}{ Why? } \\
\hline Did you like the music? & Yes & No & No comments \\
\hline Did you hear any words? & No & Yes, but not clearly & Yes, clearly \\
\hline \multicolumn{4}{|l|}{ What were you thinking about? } \\
\hline Any additional comments: & & & \\
\hline $\begin{array}{l}\text { Signature: } \\
\end{array}$ & & & \\
\hline
\end{tabular}

Figure 5: The participants of experiment no.2 have to answer the following questions.

\section{Results and Discussion}

Concerning the first experiment, about choosing the red color, the results were as follows: $50 \%$ for red, $40 \%$ blue, and $10 \%$ green. 
Mathematically speaking, and in normal conditions, the probability to choose one color from the 3 colors is $1 / 3$ or 0.33 (favorable case divided by possible cases of a combination). Therefore, and also mathematically speaking comparing the $33 \%$ (in normal situations) with the $50 \%$ in the case of the experiment (with the subliminal message) shows that the experimental hypothesis is true: subliminal messages affect and influence the participants' choice, since $50 \%$ is greater than $33 \%$. However, since the item to be chosen is a color, talking mathematically only and without taking into consideration the participants preferences for colors will lead to an incomplete analysis. In fact, the results were biased because people have preference for certain colors. When the participants answered the question "why did you choose this color?" in the questionnaire, three out of five of those who didn't choose the red answered that they thought first of the red but chose blue or green because they like it. However, three out of five who chose the red color, when asking them more details, answered that usually "red" does not mean anything for them, and they chose it without any reason (no preferences). Therefore, the results were biased because people have preference for certain colors, and listening to a subliminal message telling them to choose RED for five minutes may not be enough to influence their choice for the color (change resistance). In order to have more accurate results, the item to be chosen in the experiment should be neutral for the participants. They should not have, in normal situation, any preference for it.

For the above reason, the second experiment (about choosing a number) was carried out. People, in general, do not have preferences for numbers and especially three-digit numbers. In this case, five minutes (the time dedicated for participants in the experiment to listen to the subliminal $\mathrm{CD})$ should be enough to influence and affect their choice. In fact, after conducting the experiment, the results were as follows: $50 \%$ for $128,10 \%$ for $373,20 \%$ for $745,10 \%$ for 237 , and $10 \%$ for 452 (refer to graph 1 ). In normal cases, the probability to choose one number of the five proposed numbers is $1 / 5$ or 0.2 (in case there is no preference). Comparing the $50 \%$ of those choosing number 128 with the normal percentage of $20 \%$ will show that here also the experiment hypothesis is true: subliminal messages affect and influence the participants' choice. 

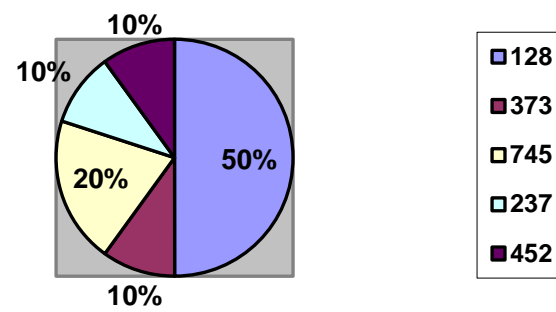

Graph 1: The results of experiment no. 2

From the ten participants in the second experiment, when asked about the reason behind their choice (number), only one answered that he prefers the number 745 because he is a pilot and this number reminds him of the Boeing airplane. All the other participants did not have any preference for any number. This participant, who had preference for the number 745, was eliminated from the experiment, and only the results of the nine remaining participants were calculated. The new results were as follows: $56 \%$ for 128 and $11 \%$ for each of the following numbers $373,745,237$, and 452 (refer to graph 2). Comparing the $56 \%$ of those choosing number 128 with the normal percentage of $20 \%$ will show that here also (in the case where none of the participants had preference for any particular number), the experiment hypothesis is true: subliminal messages affect and influence the participants' choice.
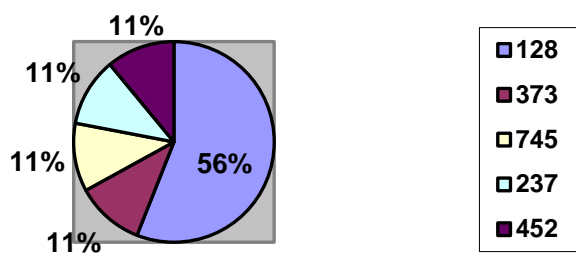

Graph 2: The results of experiment no. 2 (rectified)

In fact, according to Dr. Murphy, the subconscious mind does not have the ability to argue or dispute what it is told. Even if wrong information were given or passed to it, it will take them and accept them as true and then act accordingly. What is impressed in the subconscious is expressed later on in the conscious. However, when there is a certain preference to a certain item, time is an important factor. The subliminal message needs more than five minutes (the time specified in both 
experiments to listen to the CD) to reach the subconscious mind and therefore influence the listener's choice.

Concerning the question asked to the participants in both experiments about whether they heard any words while listening to the CD or not, none of them answered "yes", 90\% answered "No", and 10\% of the participants answered that they heard humming, but the words were not clear so they were not able to understand them. Therefore, since none of the participants heard clearly the message, the ones who chose the red or number 128, chose it because their subconscious mind heard the message (and not the conscious mind). In fact, in his website www.danielolson.com, Daniel Olson wrote about subliminal messages: "subliminal communications are messages beamed directly to the subconscious mind. Since they are below the level of conscious awareness you can not hear or understand them. Because you can not hear the communications your conscious mind can not reject the message. The subliminal message is not perceived by the conscious mind, but it goes directly to the subconscious mind.

Moreover, and ethically speaking, there are 2 different concepts regarding whether listeners to the subliminal CD should know the exact scripts masked in the CD or not. Many researchers and distributors of subliminal CD's believe that ethically speaking, the scripts should be written on the cover or the manual of the CD; on the other side, other distributors don't reveal the exact scripts but only the theme contained in the CD, because in their opinion knowing the scripts will affect the influence that the subliminal CD should have. The reason is that, as mentioned before, the conscious has developed a certain resistance to change, so knowing the message will make the conscious mind more resistant to the change; consequently, it will affect the subconscious which will need more time to change and therefore it will lessen the effectiveness of the subliminal CD. Anyway, even if the scripts are revealed or written how can a person be sure that they are correct, if the listener can not hear the subliminal message? For this reason, in the experiment, the participants were not told about the scripts on the CD, but only about the experiment; that they only have to listen to the $\mathrm{CD}$ for a certain period of time.

In addition, the subconscious mind responds according to the nature of the thoughts and suggestions brought to it, regardless to whether these thoughts and suggestions are good or bad, true or false. For example, if the conscious of a person assumes that one thing is true, even though it may be false, the subconscious mind will accept it as true, and acts accordingly. In fact, many experiments were performed on people in a hypnotic trance to show clearly how the subconscious mind does not make any reasoning, but only accepts the suggestions brought to it even if they are false. For example, a skilled hypnotist may suggest to one of the subjects that his nose 
is bleeding, or that he is freezing and the temperature is below zero. As a result, the subject in hypnotic trance will act according to the suggestions regardless of the surroundings that have nothing to do with the suggestions of the hypnotist. These simple experiments show the difference between the conscious, reasoning mind and the subconscious, impersonal and nonselective mind, and therefore, they clarify more how the subliminal messages work and affect the subconscious and then influence the listeners' choice.

However, subliminal messages are sometimes ineffective because of many reasons, some are listed below:

1. Subliminal stimuli or messages are sometimes so weak that they are not perceived by observers or listeners, and even if they are, they are sometimes nullified by other strong stimuli presented at the same time. In fact, in some cases, more than one message exists in the subliminal CD (like stop smoking and loose weight). Therefore, in order to make the subliminal CD more effective, the quality of the message should be improved.

2. Some people are very much in control of their own conscious responses to stimuli, and hence, even if they perceive subliminal messages, they can screen out any attempts to affect undesired behavior (change resistance). In this case, time is very important. Listening more to the CD will help weakening the conscious resistance to change.

3. There might be many sources of distraction surrounding the viewer or listener, which would minimize the likelihood of subliminal processing. Relaxing music will help the listener concentrate more on the subliminal message. In fact, and as mentioned previously in the article, efficient subliminal CD's should start with a certain music that helps the listener to enter in certain, so called, "alpha brainwave state”.

\section{Conclusion}

After defining the mind, its two parts were differentiated: the conscious, which is the part that does all the reasoning and thinking; and the subconscious, which is the part of the mind that executes the orders received. Then, the relation between the subconscious mind and the subliminal message was clarified, since by definition, it is the subconscious mind that subliminal messages deal with. In fact, and as mentioned previously, subliminal is below the liminal (the smallest detectible sensation), so only the subconscious mind can perceive it. Afterwards, the history of subliminal messages showed that they started as an advertising tool, and then as selfhelp tool. These subliminal messages can be used with the visual system or the auditory system.

Moreover, the interview with Mr. Zygmunt Niewiadomski, an expert in subliminal programming, enriched the research studies' part. In fact, he 
explained how exactly subliminal messages function, and clarified the main steps in recording the subliminal CD's used in the experiments. In the two experiments, twenty participants had to listen to the subliminal CD's and then they had to choose one item (the red color in the first experiment, and number 128 in the second experiment). Afterwards, they had to answer a list of questions related to their choice of the item. After evaluating the results, and analyzing the questionnaires, and eliminating the cases where participants had previous preferences for a certain color or number, the results proved that the experimental hypothesis is true: subliminal messages affect and influence the participants' choice.

As a conclusion, from the literature review and the research studies done, it can be obvious that subliminal CD's can be used for many purposes, and especially as a self-help tool. From here rises the importance of impressing, with the subliminal messages, right ideas and constructive thoughts to heal and help the listener. Moreover, results and time to achieve results depends on the individual's personality, expectations, and degree of problems that need to be changed. However, in some cases, subliminal CD's should not be used instead of a professional, medical or psychiatric therapy.

\section{Future Works}

In the experiments conducted for this research, the participants listened to the subliminal CD's only for five minutes. From the analysis of the results, it was evident that in case the participant had previous preference for a certain color or number, five minutes were not enough to the subliminal message to affect the listener's choice. Therefore, it will be interesting to repeat the experiment with new participants, with one difference: the time dedicated for listening to the subliminal CD's will be thirty minutes, for example, in stead of five.

Moreover, other kinds of experiments can be conducted to prove that subliminal messages can affect and influence not only the people's choices, but also their habits (stop smoking) or feelings (fear of height), attitudes (encouraging attitude for students in the exams periods). In this case, the scripts should be longer (five or six minutes long, but repeated several times), and the participants should listen to the CD for a period of not less than one month, whenever they can.

Finally, one interesting future experimental work can be on the athletes' performance. In fact, a three-time Olympian, peak performance expert and professional speaker, Ruben Gonzalez, in one testimonial said “A must for anyone committed to personal excellence. Olympic athletes use subliminal learning to gain an edge. So can you. Cutting edge!” Ruben Gonzalez tried subliminal messages in the visual system and it worked, so 
why not trying to improve the athletes' performance using subliminal messages in the auditory system (subliminal CD's)?

\section{References:}

4. "Subliminal Perception Manual", Doug Elrod, http://www.csic.cornell.edu/201/subliminal/ ; accessed 15 February 2005.

5. Dr. Joseph Murphy, The Power of your Subconscious Mind, pp. 618, 2000.

6. Dr. Michael D. Preston, Hypnosis Medicine of the Mind , pp. 1-38, 2001.

7. Anna Wise, The High-Performance Mind, pp. 1-20, 52-57, 1997.

8. "Subliminal CD - The Science of Self Help", http://www.subliminalcd.com; accessed 20 January 2005.

9. "Introduction to Mind and Consciousness", http://www.thebigview.com/mind/introduction.html ; accessed 15 February 2005.

10. "subliminal messeges" Daniel Olson, http://www.danielolson.com/subliminals/how_subliminals_work.htm l ; accessed January 2005.

11. "Subliminal”, The Skeptic's Dictionary, Robert Todd Carroll, http://skepdic.com/subliminal.html ; last updated 28 April 2004, accessed 19 January 2005.

12. "Subliminal Perception: Facts and Fallacies (Skeptical Inquirer Spring 1992)", Timothy E. Moore, http://www.csicop.org/si/9204/subliminal-perception.html ; accessed 20 January 2005.

13. Untitled Document, http://www.ciadvertising.org/student_account/spring_01/adv391k/hjy /adv382j/1st ; 19 January 2005.

14. "The Subliminal Scares: Subliminal Suicide?", http://www.parascope.com/articles/0497/sublim5.htm ; accessed 7 February 2005.

15. “ت "دادشو تاقيقحت" , Al Balad Journal, issue no. 374, 2" year, dated Wednesday 12 January.

16. "Subliminal Power: subliminal message software", Bradley Thompson, http://www.subliminal-power.com/mind/ ; accessed 19 January 2005.

17. "Subliminal messages", Nelson D. Berry, http://www.subliminalmessages.com/; accessed 20 January 2005. 
18. "SubliminalTech: subliminal message and subliminal tape for selfimprovement”, http://www.subliminaltech.com/faq.html ; accessed 20 January 2005.

19. "Subliminal-Studio: Subliminal Audio Software", http://www.subliminal-studio.com/messages/ ; accessed 28 January 2005.

20. "Brainwaves: Beta - Alpha - Theta - Delta", http://www.doctorhugo.org/brainwaves/brainwaves.html ; accessed 9 February 2005.

21. Steven M. Ross and Gary R. Morrison, "Chapter 39. Experimental Research Methods", University of Memphis.

22. Bruno Falissard, Evaluation et Statistique. 